This item was submitted to Loughborough's Research Repository by the author.

Items in Figshare are protected by copyright, with all rights reserved, unless otherwise indicated.

\title{
Manipulation in board game interactions: Being a sporting player
}

PLEASE CITE THE PUBLISHED VERSION

https://doi.org/10.1002/symb.396

PUBLISHER

(c) Society for the Study of Symbolic Interaction. Published by Wiley-Blackwell

\section{VERSION}

AM (Accepted Manuscript)

\section{PUBLISHER STATEMENT}

This is the peer reviewed version of the following article: HOFSTETTER, E. and ROBLES, J., 2019. Manipulation in board game interactions: Being a sporting player. Symbolic Interaction, 42 (2), pp.301-320, which has been published in final form at https://doi.org/10.1002/symb.396. This article may be used for noncommercial purposes in accordance with Wiley Terms and Conditions for Use of Self-Archived Versions.

\section{LICENCE}

CC BY-NC-ND 4.0

\section{REPOSITORY RECORD}

Hofstetter, Emily, and Jessica Robles. 2019. "Manipulation in Board Game Interactions: Being a Sporting Player". figshare. https://hdl.handle.net/2134/37252. 
Running head: Manipulation in board game interactions

MANIPULATION IN BOARD GAME INTERACTIONS: BEING A SPORTING PLAYER

\author{
Emily Hofstetter ${ }^{1}$ \\ Linköping University \\ Jessica Robles \\ Loughborough University
}

1 Department of Culture and Communication, Linköping University, Linköping, 58183 Sweden. Email: emily.hofstetter@liu.se. 


\title{
MANIPULATION IN BOARD GAME INTERACTIONS: BEING A SPORTING PLAYER
}

\begin{abstract}
Deception and manipulation are expected in strategic gameplay, but how do players negotiate what counts as acceptable kinds of manipulation? We compare three examples from a corpus of 30 hours of competitive board game play, using conversation analysis to examine how players orient to the reasonableness of manipulations. We show that contingencies of timing of the attribution and receipt of the manipulation are as morally concerned as manipulation itself. Players organize their negotiations of acceptability around the concept of a "sporting" player or move. The "sporting" resource shows one situated members' method for collaboratively managing fairness and morality in play. A video abstract is available at https://youtu.be/IlaEw6FUxw.
\end{abstract}

Keywords: manipulation, board games, conversation analysis, sporting, reverse psychology 


\section{MANIPULATION IN BOARD GAME INTERACTIONS: BEING A SPORTING PLAYER INTRODUCTION}

In accomplishing everyday social activities, research has shown that humans orient to making their behavior intelligible and available for intersubjective understanding, and that to do so is to act in a moral way (Garfinkel 1967; Grice 1975; Stivers, Mondada, and Steensig 2011). Indeed, such sense-making is the backbone of society and social interaction. In playing competitive games, however, we often pursue strategies, and must necessarily withhold those strategies from other players, breaking the norms of intersubjectivity. In other words, we lie, sometimes by omission, and sometimes by active diversion or deceit. Not only does the deceit itself contradict norms, players' guesses and attempts to uncover strategies likewise go against epistemic norms of rights-to-know (Raymond and Heritage 2006; Stivers et al. 2011). When Sacks wrote "Everyone has to lie" (Sacks 1975), he was investigating how we frequently accept certain lies as normal or expected (e.g., responding "fine" to a "how are you" greeting, despite potential feelings to the contrary). In contrast, the question of what occurs when people orient to deceit as deceit has rarely been examined in interactional studies. This is likely due not only to the paucity of such instances in most interactions, but the difficulty in confirming them.

In this paper, we examine a setting in which people regularly orient to and negotiate the acceptability of deceit: competitive board game play between adults (30 hours of game play). Board games provide a medium that in some ways exploits, abuses, and literally plays with norms of intersubjectivity and deceit, to such an extent that some studies have considered games to occupy a "magic circle" in which normal moral concerns do not apply (Huizinga 1949; Salen and Zimmerman 2005). In this paper, we examine how players negotiated the acceptability of attributed manipulations and deceptions, showing that players use and orient to being a 
"sporting" player as part of organizing these negotiations. Manipulations occur when a prior turn or action is re-labeled by participants as having a different action (often also including a different stake and motive) than that which was previously established, and we focus in this paper on these moments when they became contested in the data. Players must manage the social implications of attributing (implying, labeling, calling, etc.) manipulative behavior, in addition to the concerns of actually doing such behavior themselves.

In the next sections, we review how games have been studied in interactional work and how symbolic interactionism has dealt with strategy and manipulation, as well as introducing the concept of the "sporting" resource.

\section{Games from an Interactional Perspective}

Games have been studied from a variety of interactionist traditions - in symbolic interactionism for the structured roles and fantasies that games provide (Waskul and Lust 2004), and in ethnomethodology and conversation analysis (EMCA) as a means to examine seriousness and playfulness (Goodwin 1985; Holt 2013) and as a convenient way to collect interactional data (e.g., Fox and Thompson 2010; Viney 2015). However, few studies have investigated how games function as games for the players, during live gaming. The main exceptions are studies of participant orientations to rule use (Kew 1986; Liberman 2013), and management of roles in role-play games (Linderoth 2012; Waskul and Lust 2004). These latter are especially relevant for this study, as game rules ostensibly exist to manufacture fairness, and yet the studies found that players frequently treat rules as flexible and changeable according to the desires of the players in that sitting. As such, the rules, as well as fairness itself, are negotiated resources.

Since games come with normative expectations and invoke rules of fairness and good conduct, there is a moral dimension to gameplay. The interactional work on morality in play has 
repeatedly found that what counts as moral, as with what rules to follow and how (Sidnell 2011), is a negotiated matter, and one that is live for participants throughout the interaction (Bateman and Butler 2014). In other words, the right and wrong way to play games is constructed through the interaction and defined by how participants orient to game participation as legitimate, ordinary, accountable, sanctionable, and so forth. The research above addresses whether game moves are acceptable in the sense of valid or legitimate_-Can that move occur?"-whereas our study concerns instances of acceptability rather than the validity of events in the games. The negotiations around acceptability of manipulation concern instances where multiple moves are equally valid and possible, but one move or action may be more fair, selfish, strategically advantageous, and so forth, than other moves. In this way, negotiations of unacceptability focus on players' conduct as good players, not only whether their move can stand.

The role of fairness and moral play has recently received more attention in EMCA literature (e.g., Evaldsson 2004; Evans and Fitzgerald 2016; Stivers et al. 2011). However, the majority of EMCA work on play focuses on children's interactions, and where play among adults is examined, it is usually not in the context of morality. Where games are examined in EMCA, the focus is largely on video games (e.g, Davidson 2012; Piirainen-Marsh and Tainio 2014; Reeves, Greiffenhagen, and Laurier 2016; Sierra 2016), while board games remain unexamined (despite frequent use in data, see above). Games do have different contingencies from other interactions, just as true for any interaction surrounding a particular activity or institution. Part of the purpose of examining these interactions is to discover what those contingencies are.

Evans and Fitzgerald (2016) are the main contributors to understanding adult moral orientations during games (for children, see, e.g., Theobald and Danby 2019). Their study shows 
how members negotiate the acceptability of aggressive behavior during basketball practice. In particular, the process of unpacking game-relevant categorizations shows players engaging in moral reasoning to determine appropriate next steps. We will show similar orientations in our data in this paper. However, our analysis looks at attributed intentions of players (i.e., the attribution is one description or version of understanding the action, among others, see Sidnell 2017), whereas Evans and Fitzgerald's players are less (if at all) concerned with matters of deceit. Outright deceit has also been ignored in EMCA studies, mostly due to its supposed unavailability (see below). Morality, like deceit, is only "overtly distinguishable" when a breach occurs (Theobald and Danby 2019).

A key concern in prior work about acceptable play is Huizinga's (1949) concept of the "magic circle," whereby behavior during play is "marked off" and separate from the rules of everyday life. What is acceptable during a game is supposedly different from what is acceptable during everyday life; for example, taking an opponent's chess piece has a meaning within the game (enacting a strategy, moving towards winning, etc.), that it does not have outside of the game (moving a game piece around the board has no sense of aggression, competition, inevitability, outside of the game, according to the magic circle). This concept has been developed in many studies and theories (see Stenros 2014), including extensive criticism (e.g., Consalvo 2009). Much of this criticism argues that the magic circle is not or cannot be completely distinct—likewise with Bateson's ([1972] 2006) frame of play. Juul (2008:64) proposes a version more in line with symbolic interactionism: "the magic circle is best understood as the boundary that players negotiate." However, if this is the case, we should not assume the circle is present a priori. Interaction does not become something else by virtue of context, but context is perpetually re-indexed and constituted, making it highly flexible and not 
distinct from the methods used in any other context. As we will show, the acceptability of manipulations in particular is negotiated via a play-related members' category ("sporting"), but the negotiations do not hinge on whether it is play or not-play, nor whether the move is valid play. In short, rather than assuming the presence of a magic circle a priori, our approach gives priority to how game participants orient to game contingencies as a local matter of the gameplay itself. The goal of interactional analysis is not to apply analysts' categories but to focus on what participants themselves say and do in situ.

\section{Strategy in situ}

In analyzing everyday interaction, ethnomethodology and conversation analysis pick up the realtime component, and especially make use of Goffman's, and Garfinkel's (2006), concept of members' analysis: any intentions that are determined are attributed based on the member's/audience's understanding, not the speaker's inner state as determined by the analyst's interpretation of the participant's efforts at that moment. However, this analysis precludes the analysis of strategy, if one presumes that to analyze strategy must involve knowing the privately held strategies, intentions, or goals of players (Heritage 1990; but see Edwards 2008). We agree that player intentions are not analyzable from recorded interaction, nor are they available to participants - but players (and everyday speakers) remain oriented to other people as goaloriented organisms (Sidnell and Enfield 2014). As such, they engage in attributing strategy, much as they engage in attributing action (see Sidnell 2017). These attributions have social contingencies that are analyzable, which is what this paper undertakes. Players are members too, and strategy is one of their concerns.

Goffman has analyzed motivation and strategy (1971), as a members' concern; his analyses of hypothetical instances provides an excellent starting point to understand the 
contingencies of strategic play (such as the assumption of motivation, the problem of doubt, and the double bluff problem). However, Goffman's analysis concerned how games can and cannot provide a metaphor for real interaction (a common issue in social analysis, see DiCicco-Bloom and Gibson 2010). We are not the first to raise concerns that games cannot solely be considered as metaphors (e.g., Puddephatt 2003), but analysis of actual game play as arising from interaction is less common. Though Goffman may touch on actual game contexts, there is no work examining how players manage in real time the contingencies that Goffman proposes through their interactions. Frame analysis (Goffman 1974), for instance, has limits when analyzing real interactions that cannot be paused and examined. While players report "taking on the role of the other" (for example, in chess, Puddephatt 2003, and in role-playing, Waskul and Lust 2004)_which is especially relevant for attributions of manipulation as in this paper-how that is achieved and negotiated in situ through the interaction requires far more attention and detailed analysis (the closest to examining this is in online role-playing adventure, Linderoth 2012).

In a similar vein, players have other contingencies to manage besides strategy, including interactional requirements like turn-taking, and social requirements such as the long-term effect of moral behavior on relationships with other players. Purely focusing on strategic contingencies (as in Goffman 1971; Schelling 1967) requires a willingness to deceive for individual (self) benefit, without reference to more collaborative motivations. Studying live game interactions brings us to the intersection of strategic possibilities, interaction management (norms, turntaking, moral work) and real-time participant agency. Game players exploit Garfinkel's and Goffman's rules of audience/members' interpretation. If ordinary interaction involves making oneself intelligible to other members, employing deceit involves producing an alternately intelligible action. To do manipulation is a carefully managed process of making the deceit 
unintelligible, but making another plausible alternative intelligible. We focus on manipulations in this paper because they are typically shorter-term than a whole-game strategy. The manipulation often takes advantage of a temporary set of variables, and the completion of the process (where they are attributed) often occurs within a few minutes, instead of hours.

\section{Sporting play}

We are using the vernacular definition of sporting (Sporting, from the OED": "c: practising or exemplifying the ideals of a particular sport; characterized by sportsmanlike conduct... fair, generous, resilient..." where sportsmanlike is "b) Resembling (that of) a sportsman; ...worthy of or befitting a 'good sport'; honorable, generous, fair, resilient"), where such qualities are negotiated, displayed, and made accountable by players in the data.

We have chosen "sporting" play for its more gender-neutral qualities, and also because it is a word that is more readily applicable to non-humans (e.g., sporting moves or rules, not just sporting players). In particular, what fits around the sporting concept in this data is both the accomplishment of fair actions, as well as the cheerful receipt of actions regardless of consequence. We will show (a) how players orient to the timing of manipulations (when it is done, and particularly when it is revealed) with respect to turn order, (b) how they orient to whether the manipulation impedes or promotes the overall equitable access for all players to achieve game goals such as winning (i.e., whether it promotes continuation of fair play), and (c) likewise that even in the face of the lack of these features, players must show resilience and willingness to suffer the ups and downs of the game events (see Jefferson 1984b for what this looks like in everyday interaction).

\footnotetext{
2 "Sporting, adj. 1c" Oxford English Dictionary online, Third Edition. Retrieved January 1, 2017 (http://www.oed.com/view/Entry/187490).
} 


\section{METHOD}

This study examines the interactions between board game players at moments where deceit is attributed. Our approach is used across symbolic interactionism, discursive psychology, and conversation analysis in locating the participants' sense of acceptability and morality in their own orientations and displays within the interaction. Coming out of conversation analysis (see Sidnell 2010), we rely on the way in which the "next interactional turn" in a recording makes available a speaker's interpretation of the prior turn that occurred. As such, our understanding of what contingencies affect the morality or the "sportingness" of any given attribution of manipulation arise from the social interaction of participants, within game play. Players become accountable for each prior turn, and this calling-to-account is the means through which the fairness of a move or turn is negotiated.

The study was done under approval of a UK university ethics board, and all players were adults who gave consent to record. For this paper, any non-competitive games in the corpus were excluded, as were bluffing games (game in which each move can be assumed to be a deception, as that is what constitutes play), leaving competitive strategy games (see Game specifics below). The remaining 30-hour corpus includes data collected from board game cafes and informal gatherings (13.75 hours), undergraduate students playing games for research participation (1.75 hours), and online sources (YouTube, where gamers may post "play-throughs," 14.5 hours). The collection for analysis was formed of instances with overtly attributed manipulations (41 observed). These did not occur in every game. The three selected for analysis here were chosen to represent the more common pattern of attributing a manipulation, with minimal complaint (Extracts 1 and 2), and one deviant case with an argument arising from a manipulation attribution (Extract 3). All three demonstrate the way the attribution itself can be accountable, and that the 
accountability is spread among several players, not just the one who is attributed to have manipulated. The transcripts presented follow Jefferson (1984a) notation.

All the manipulations presented are what Bergström (2010) calls "metagaming," or talk that surrounds the game but does not itself constitute game moves. Thus, one has not moved $b y$ stating "So I need an orange," but indicated being in the process of deciding a move. In contrast, talk such as “done” or "it's Tim's turn" would not normally constitute metagaming. In the data corpus, there are no instances yet whereby someone attributes manipulation to a player based on game moves. Instead these are attributed to clever strategy. As a result, non-move manipulations may be negotiated and issues concerning potentially unsporting play may arise, but game moves that literally manipulate another player in the colloquial sense of the word (e.g., a chess feint, or a series of checking moves in chess that force a player into a checkmate) do not seem to be potentially related to sportingness.

\section{Game specifics}

There is not space to detail all the rules of each game in each extract. The games in the extracts selected were all games wherein all players competed with each other, with only one possible winner. These games do not require deception, although masking of strategy may be considered wise. The games did not have a high degree of luck (e.g., what cards one happens to draw, or what dice roll one gets). All the games were "modern" board games that are often unknown outside of the gaming community (more well-known games such as Monopoly or Sorry! were not used). Strategies change over the course of the game, and are hence unknowable by the researcher, but can become part of intersubjective understanding over the course of the game as players recognize game-piece formations, or attribute motivation behind moves. 
The manipulations in this paper are moments when one player "gives off" one performance (e.g., criticizing a move) that suggests one particular strategy while privately pursuing an alternate strategy (e.g., actually disliking the move, and hoping that fake criticism will make the opponent rethink and change their move). Again, only attributed manipulations will be discussed: when a player attributes that some other player has done a manipulation by relabeling some prior turn or move with a new understanding. It is the act of attribution and its consequences that are of analytic interest in this paper.

\begin{abstract}
ANALYSIS
The attribution of a manipulation is a morally fraught exercise for all parties, not just for the player doing the manipulation. Manipulations can be done via many actions (giving advice, withholding information, offering, praising, etc.), but they share concerns for whether it is an appropriate, fair, or sporting activity. In this analysis, we show how players negotiate the acceptability of a manipulation, and how timing can affect the acceptability of making manipulation public. In the first two extracts, a manipulation is attributed and managed with minimal complaints from the victim (the one suffering the loss due to the manipulation). The third extract will show an instance where the attribution involves an antagonistic argument.

In the first extract, Nancy plays a card that allows her to take a cube from another player (L1-8). These cubes are used as resources to get points in the game, so this will earn Nancy points, and cost the victim points. Nancy has the option to take from one of two potential players, Jack and Tim (L11-14). Both Matt and Jack offer advice on how to make the decision (L15-31). Jack's offer (L17) is later characterized as manipulative.

Extract 1: TT Lords of Waterdeep 31:54 You're a freakin' jedi 3

${ }^{3}$ Information about Lords of Waterdeep is available at https://boardgamegeek.com/boardgame/110327/lords-waterdeep.
\end{abstract}




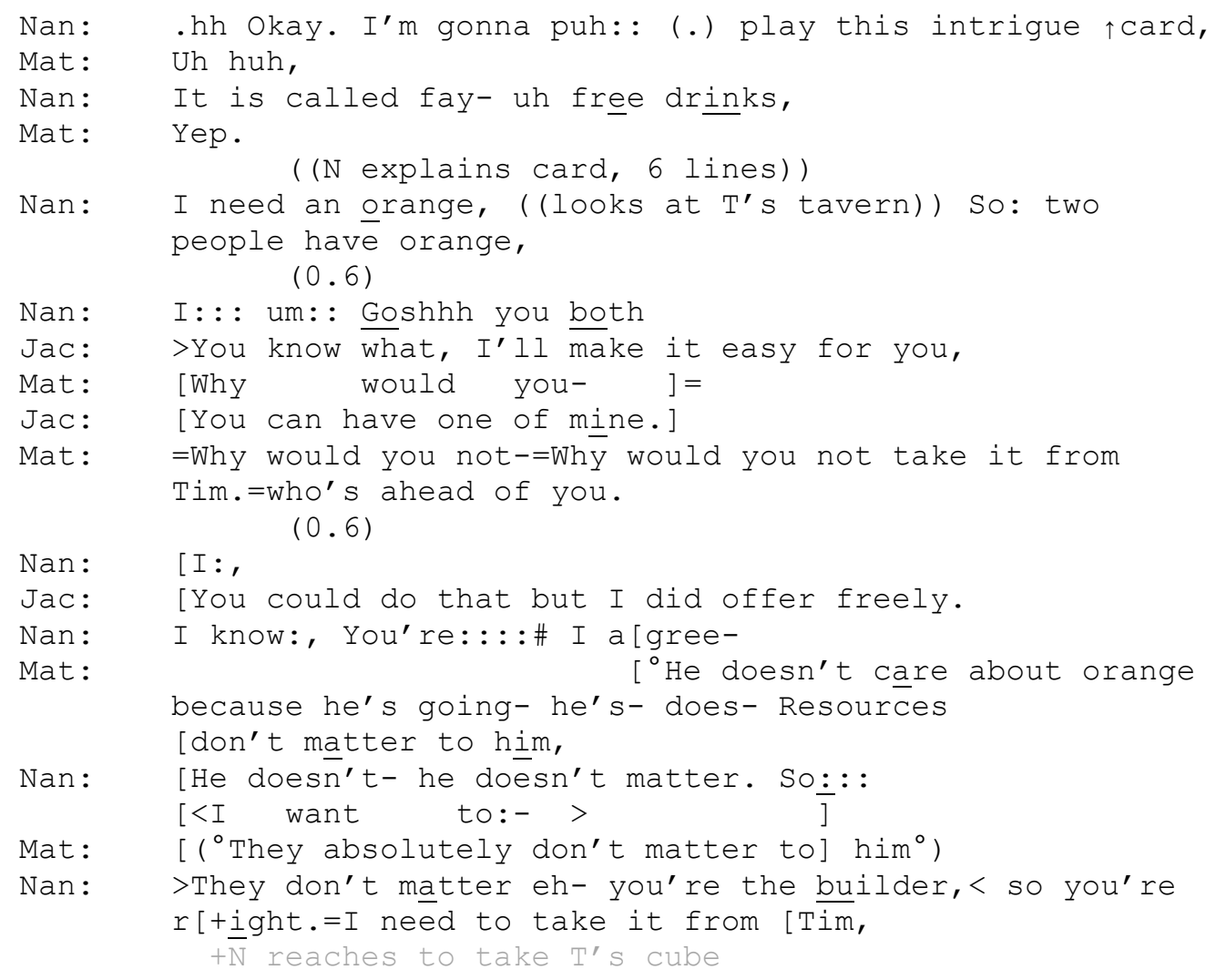

Nancy recruits possible assistance at Lines $11-14$ by stating the facts of her situation-she needs an orange cube, two people have orange - and finally hesitation about which to choose (L13-14). All players in the corpus regularly do actions that account for "thinking" or taking a long turn, regardless of their competence level in the game. These accounts can recruit advice. The game move itself (the taking of the cube) is not made accountable; it is sanctioned by the card. Nancy legitimizes her move as she goes, announcing her move (L1) and then reading the card (L3-11). Such narration is common, and makes game moves available for comment, sanction, and resistance from other players. Matt repeatedly consents to, and thus legitimizes, Nancy's moves (e.g., L2, 4), so the very act of "stealing" has been publicly accepted (this matches Levinson's [2013] description of the process of ratifying the validity of moves and rule following). All that remains is to decide who will be the victim. 
After Nancy's hesitation, Jack offers his cube (L17), just as Matt highlights that Tim has more points than Nancy, so the strategic choice that would improve Nancy's standing in the game is to take from the person ahead of her, Tim. Matt also stands to benefit from Tim losing a cube, and more so than if Jack loses a cube, as Jack is already in last place; so, Matt's advice pursues his own game agenda, as well as aiding Nancy's. Tim, who stands to lose the most, makes no comment. Jack and Matt continue advising Nancy in different directions (L22-29), with Matt providing strategic rationales, and Jack pursuing his offer (L22). Nancy ultimately accepts Matt's advice, on the basis of confirming that Jack's offer is disingenuous (L27-31) (see Shaw and Hepburn 2013 on being an advice recipient). Now comes an explicit attribution of manipulation, from Tim.

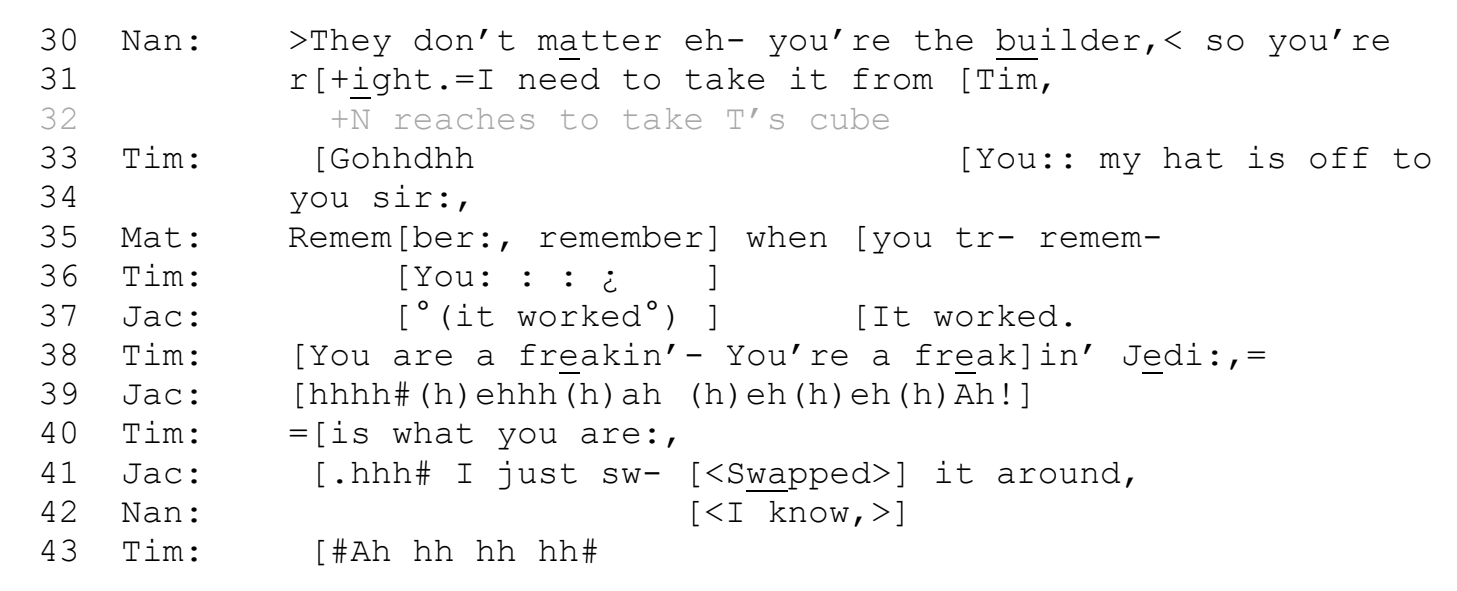

Tim has withheld comment until Nancy picks up his cube, in other words until the outcome of the discussion earlier (L11-32) has become certain, at which point he lets out a breathy expletive (God, L33), indexing some complaint. However, Tim begins to praise Jack, saying “my hat is off to you sir:," (L33-34). In using sir (Jack) rather than ma'am (Nancy), Tim suggests that Jack been the primary agent in creating the situation, not Nancy (although it was Nancy's game move). 
Tim continues with more praise, "You're a freakin' Jedi:," (L38). The category of "Jedi" suggests that Jack has especially strong abilities to manipulate (the Jedi being characters in the Star Wars film franchise capable of supernatural feats of mind control). Tim has made an alternate account of Jack's actions available (Sidnell 2017), in moving from "generous offer" to "manipulation." These statements constitute the attribution of manipulation. Jack's turns contain design elements emphasizing the offering nature of his action: he offers to make it "easy" (L15) for Nancy, he explicitly categorizes the action as an "offer" (L22), and he does so "freely" (L22), suggesting he is being altruistic. These are all characteristics associated with being a sporting player, in doing an action for the sake of generosity. Tim re-labels these turns as manipulative, and skillfully so. In other words, Jack has done what is colloquially called "reverse psychology" - making an action with the expectation that it will lead to the opposite outcome from what is performed publicly as desired by the speaker. Jack describes this as "I just sw- $<$ Swapped $>$ it around" (L41). Jack has not yet claimed that this potential manipulation was intentional- he could have legitimately been offering the cube. However, Tim's turns are sufficient to indicate that Tim, at least, treats Jack's action to have been intentionally manipulative; he puts the ascription of manipulation on public record. At Line 37, Jack aligns with this interpretation (whether it is an "accurate" portrayal of Jack's previous action is irrelevant), claiming that "It worked" and thus claims that the reverse psychology was done on purpose.

We have so far called Tim's turns "praise," but they are not unambiguously so. To call someone a Jedi is also to categorize them as a manipulative player - to contrast the earlier sporting work done by Jack. The utterance "my hat is off to you sir:," (L33-34) performatively 
concedes defeat, exaggerating the politeness. "Sir" (L34) is hearable as ironic, adding a formal address term to an informal setting. By re-describing Jack's actions through a praising action (with some irony), Tim avoids overt complaining and being a sore loser, and still puts a manipulation ascription on the record. The only sign of his upset is the expletive response cry (“Gohhdhh” L33), with a breathy, sigh-like quality (Hoey 2014). Tim not only treats Jack’s manipulation as clever and valid play, but reacts in a sportsmanlike fashion himself, by not overtly complaining and in fact complimenting his opponent. Tim shows resilience and willingness to suffer the loss by putting his reaction to the loss in the "vehicle" of praise (Schegloff 2007).

Tim's reaction also does not make Nancy and Matt accountable for the action. Although it was Nancy's card, and game choice, that permitted her to take the cube, Tim is holding Jack accountable for the negative consequence. Typically, one would "take a hat off" to the person who has performed the game action, but by claiming that Jack engaged in manipulation, Nancy's agency and accountability is removed. Furthermore, despite Matt's advice to Nancy that targeted Tim (recall that Matt also stood to benefit more from Tim losing a cube than from Jack losing a cube), Tim addresses Jack's manipulation rather than Matt's advice.

In Extract 1, we see several players use the resource of being a sporting player: Jack as part of his "freely" offered cube (in being seemingly "generous," he is enacting a sportsman-like quality), and Tim negotiating both a complaint and a compliment as a sporting victim of a strategy. The use of manipulation in this context is treated as highly skilled and properly competitive, rather than deviant or unacceptable.

The (alleged) manipulation in Extract 1 was revealed after completion of the move. Manipulations can be attributed while a move is still in progress, as seen in the next extract. In 
this game (Tash Kalar), Adam has played a card which allows him to move two of his opponents' pieces on the board. Having an opponent move one's pieces is highly disruptive to completing game goals, as piece location has serious implications for accomplishing moves in this game. It is possible that Adam might move the pieces somewhere beneficial, as he does not know what spots are useful for John and Kat, but it is unlikely.

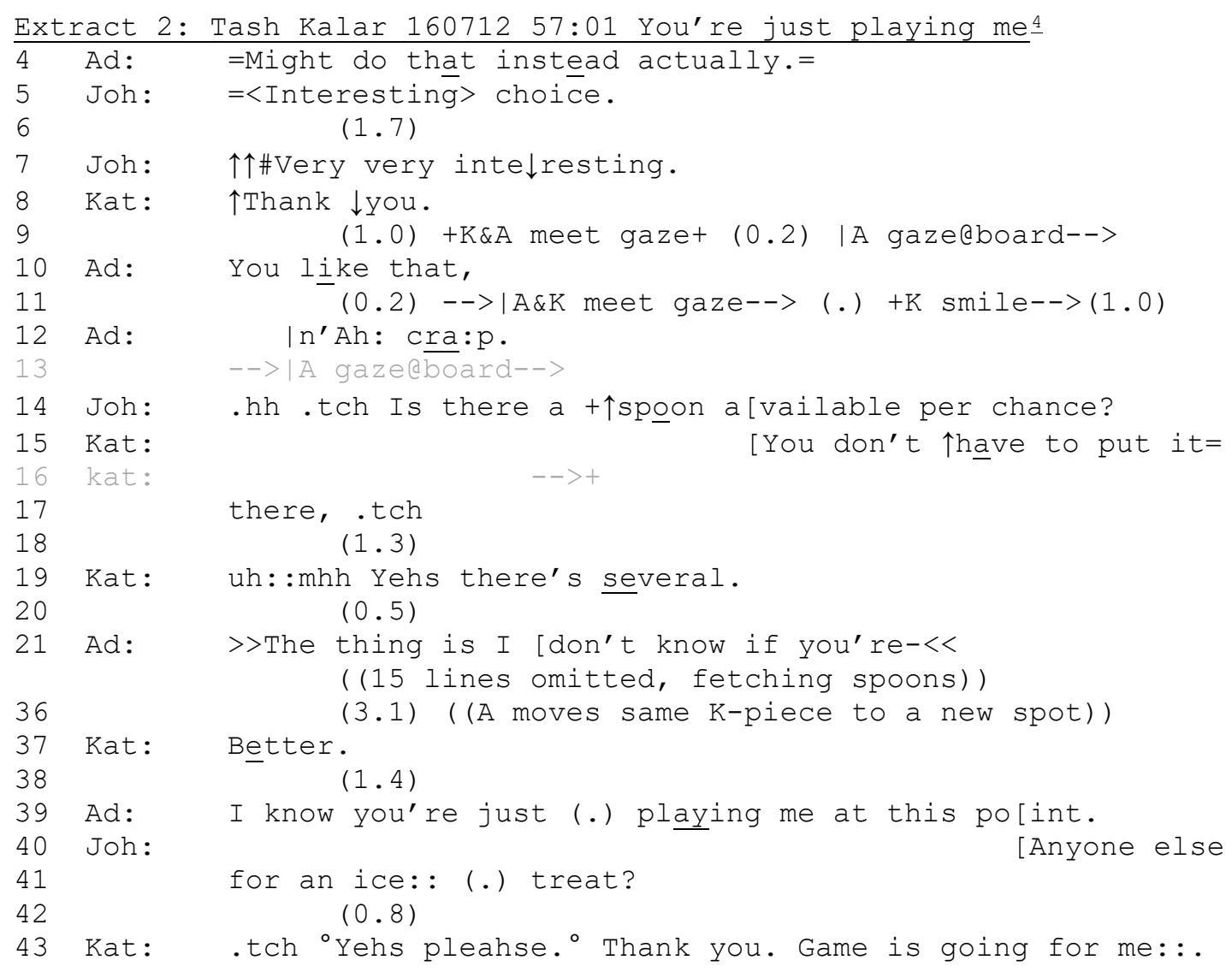

John and Kat use different practices to receipt Adam's move. When Adam finishes his

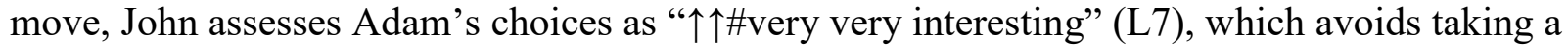
positive or negative stance (see Pomerantz 1984 on assessments). This is similar to Tim's strategy in Extract 1 of avoiding comment, in that it avoids revealing how the move has impacted

\footnotetext{
${ }^{4}$ Tash Kalar information is available at https://boardgamegeek.com/boardgame/146278/tashkalar-arena-legends.
} 
John's plans. Kat thanks Adam for the movement of her pieces (L8). It is highly unusual to thank another player for moving one's pieces elsewhere - usually this causes problems for the player and is grounds for complaint or lament. Kat is suggesting that Adam has aided her, instead of hindering her. Adam initiates repair (L9-11). Kat confirms her stance by smiling, and Adam now laments his own move with "n'Ah: cra:p" (L12), suggesting he takes her expression of gratitude as genuine.

Kat's display of gratitude presents problems for Adam, as seen in his confirmation check (L10) and his uncertainty (L21, 39). It is strategically better for Adam to avoid placing the piece in a way that makes Kat thank him; thus it is relevant for Adam to determine whether she is bluffing, given how unusual it is for someone to openly display gratitude for this kind of move. Players should know that Adam is attempting to cause damage, not gratitude (see Livingston 2008 on the ways moves can be witnessable), and so if Adam has moved in a way that truly helps Kat strategically, it would be strategically better for her to pretend to be unhappy and fall in line with that expectation.

Adam first displays his interpretation of her communication as genuine; he laments his mistake with an expletive (L12). Adam then begins to shift what action he ascribes to Kat's turn (Sidnell 2017), towards attributing manipulation. The first indication that Adam thinks Kat has been manipulating him comes on Line 21, " $>>$ The thing is I don't know if you're- $<<"$, which may have been a statement that he was not sure of Kat's intentions. Adam's turn (L21) does not address John's ongoing search for spoon, suggesting it is about the game (his gaze is also towards the board). When Adam moves Kat's piece again, she praises the move again. However, this time Adam does not respond with the same dismay as before (L12), and states that he now knows that Kat is manipulating him and using "reverse psychology," as with Extract 1 above. 
Adam phrases this as, "I know you're just (.) playing me at this point" (L39), where "playing me" idiomatically refers to exploiting a person, or to use them in the sense of playing an instrument. Adam makes the alternate version of Kat's "thank you" intelligible — manipulation rather than genuine praise - and also indicates that this is a newly acquired understanding, happening "at this point." Relatedly, though not identically, Mikesell et al. (2017) find that "I know" as a complete response can act as a correction, resisting the categorization of the recipient (in this case, Adam) as an unknowing party. Adam is both ascribing manipulation and doing the ascription as an updating action of his awareness of the manipulation.

Adam's statement on Line 39 accuses Kat of manipulation, but Adam does not sanction Kat for having manipulated him. It is possible that his attribution of "just (.) playing me" (L39) is hearable as a complaint, but if so it is a minimal complaint. Adam's utterance, in fact, accounts for his own behavior — for having been duped. In this self-accounting work, we see again that manipulations do not involve straightforward accountability for only the manipulator, but also for other parties. Again, there is a mild complaint involved in having been played (L39), but nothing further, and the victimization at the hands of a manipulation is let pass.

Both Extract 1 and 2 show the victims assessing the manipulation as acceptable through a minimal complaint ("You're a freakin' jedi" and "I know you're just playing me”). In so doing, they make public their willingness for such actions to exist in the game, while also expressing their stance towards the action and their potential victimization. This stance fits the definition of sporting — of having the good temper to accept the downs of the game alongside the ups. Not all complaining in the corpus is so minimal, however. There are instances of outright argument and hostility. The next extract shows an instance of this behavior. In the following extract, one player (Dave) attributes a manipulation to another (Cal), saying that Cal was counting on Robert not 
noticing a potential move that would hinder Cal's strategy. Cal treats Dave's attribution as revealing his strategy, and as manipulative advice to Robert in and of itself. Dave's interference is treated as a serious infraction, and leads to an argument.

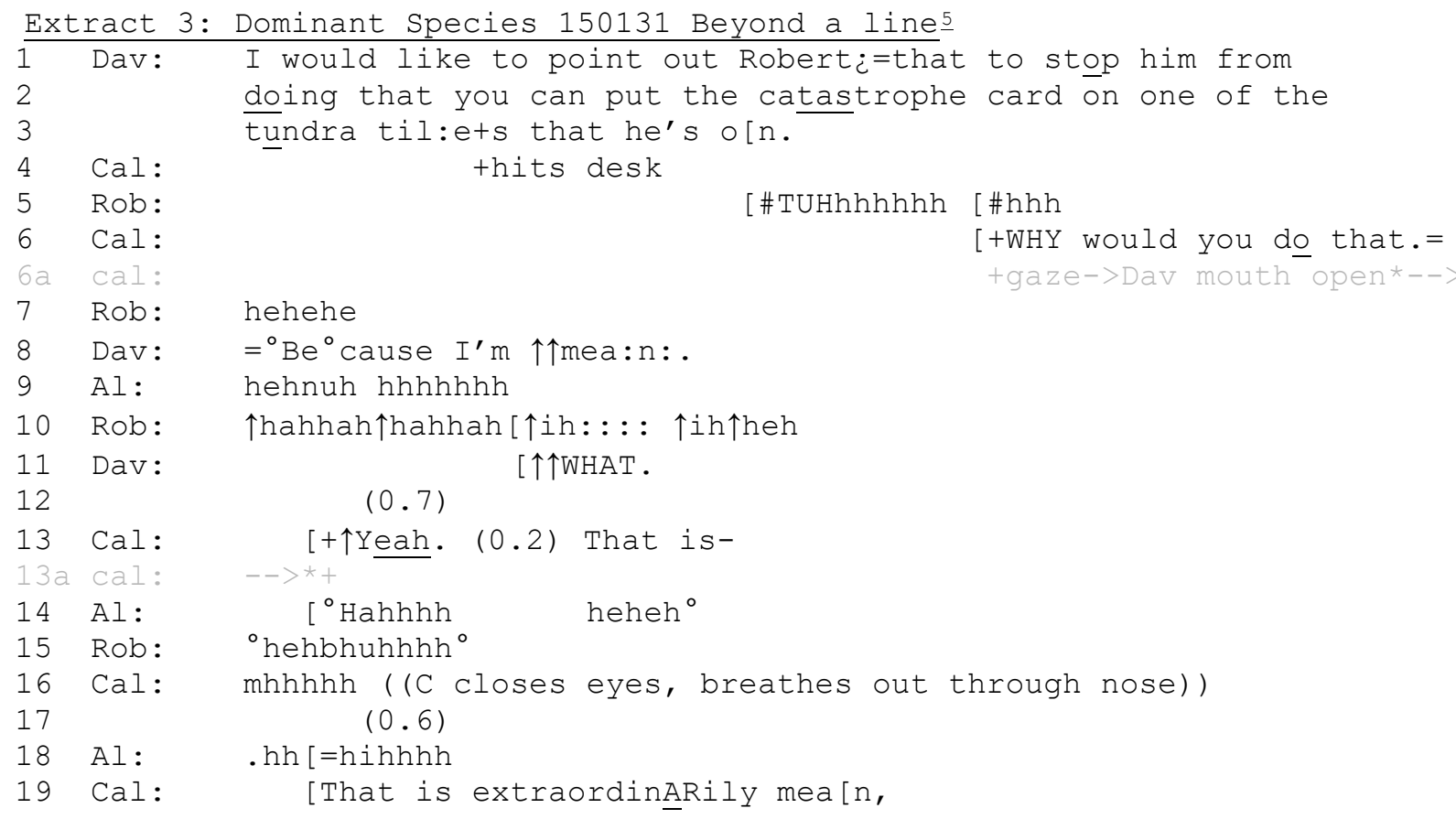

At Line 6, Cal explicitly calls Dave to account for giving Robert a suggested path for

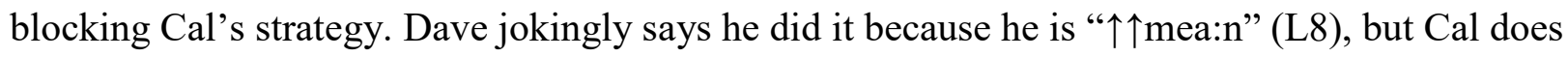
not ratify this account or the playful stance, holding gaze at Dave instead. Dave initiates repair,

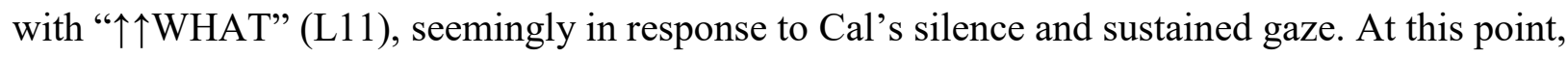
Cal repeats Dave's account, with less exaggerated pitch, and in doing so, transforms the joke into a serious accusation of immoral behavior. Cal accounts for this accusation below (omitted L2021 are laughter):

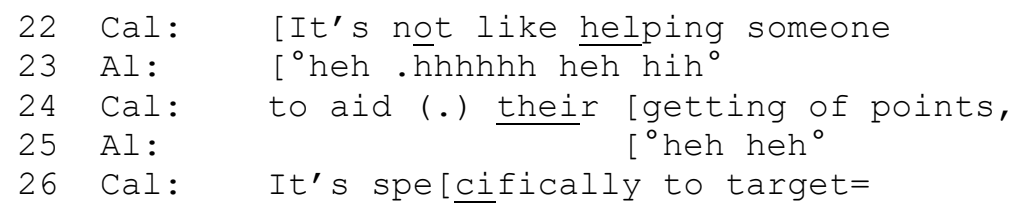

${ }^{5}$ Dominant Species information is available at https://boardgamegeek.com/boardgame/62219/dominant-species. 


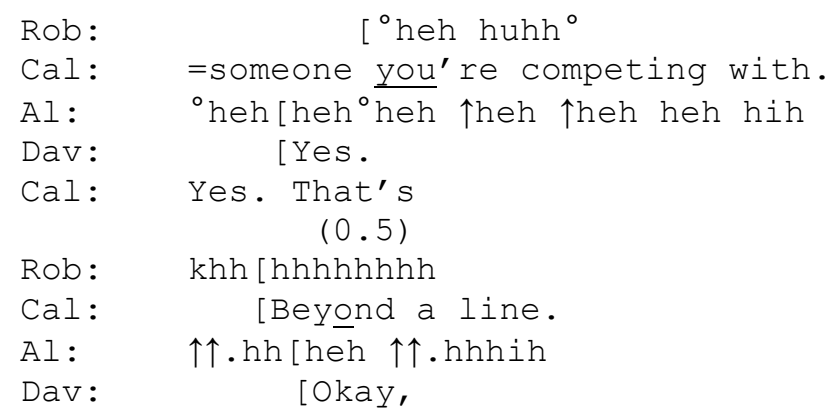

Cal's reasoning for accusing Dave of being "extraordinARily mean" (L19) is that Dave's actions are not altruistically advising someone, but unfairly targeting Cal — the "someone" (L28) with whom Dave is competing. In Cal's complaint, Dave's advice is portrayed as only serving Dave's own purposes, rather than being altruistic advice. This makes an alternate version of the action available: manipulation. Further, Cal explicitly argues for the unacceptability of Dave's action, underscoring the moral concern in the argument. To purposefully hinder one player over other players is, according to Cal, "Beyond a line" (L34), and unacceptable. This notion of "targeting" appears frequently in the data corpus, as a means of complaining about unfair play. It claims that a disproportionate kind of competition has been focused on the victim, which hinders the victim from playing on level ground, representing behavior that is not sporting. Cal's explanation specifically highlights this contrast between acceptable ("helping someone to aid (.) their getting of points," L22-24) and unacceptable ("to target someone you're competing with." L26-28). Cal continues this reasoning (L37-43) before Dave responds (L50-55):

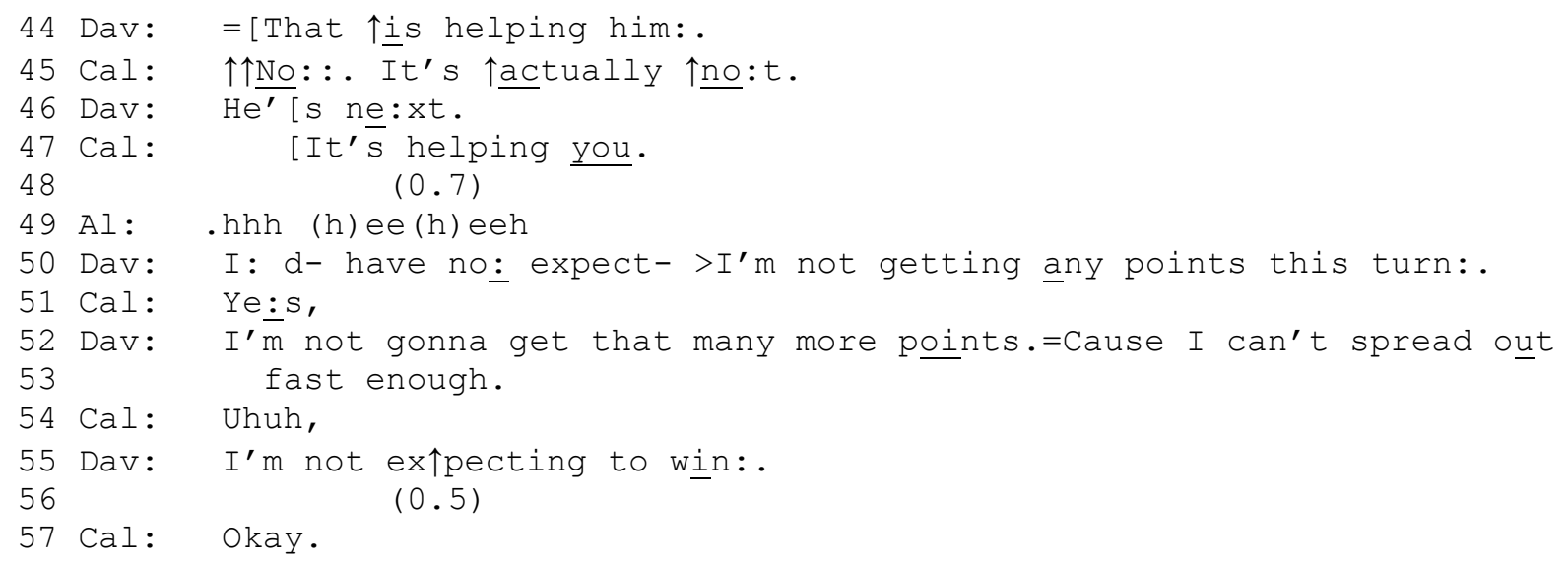


Here we see the most antagonistic sequence, with several countering turns made in succession. Dave claims that his earlier action is helping Robert after all (L44). Cal contradicts this, saying "It's helping you" (L47), where the emphasis on "you" serves to emphasize the contrast with helping Robert. This continues to portray Dave as self-serving, rather than helpful, furthering both the attribution of manipulation and the unsporting description. Dave's next account is that he cannot get the points to compete with or win against Cal, citing evidence on the board that he cannot earn said points (L50-55). Once Dave claims he is not expecting to use any competitive advantage for the ultimate purpose-winning - Cal accepts the account (L57). In claiming no expectation of gaining points, Dave provides what ends up being an effective counter-argument, that his action could not have been self-serving if it was not done as part of winning.

Cal himself is also vulnerable to being treated as unsporting, and participant orientations to this can be seen in two ways. First, Dave's resistance to Cal's upset, or further accounting, portrays a contrast between himself (Dave) and Cal. Dave is not going to get "any points this turn:" (L50) and is "not ex个pecting to wịn:," whereas Cal is going to receive points this turn, and yet is acting in a highly competitive way. Despite Cal having the upper hand, he is complaining strongly, which is not a sporting acceptance. Second, Robert and Alice continually giggle throughout this exchange, showing an orientation to the problematic, uncomfortable nature of the argument on the table (see Holt 2012; Melia 2015; Potter and Hepburn 2010).

However, the dilemma is not yet over. Robert has knowledge of Cal's move that he "should not" have, that he has gained unfairly, and he must decide whether to act on such knowledge and gain the "unfair" advantage. As a result, Robert has to account for his behavior, which he does below:

$$
\begin{array}{ll}
58 & (0.7) \\
59 \text { Al: } & \circ \text { aheh, }
\end{array}
$$




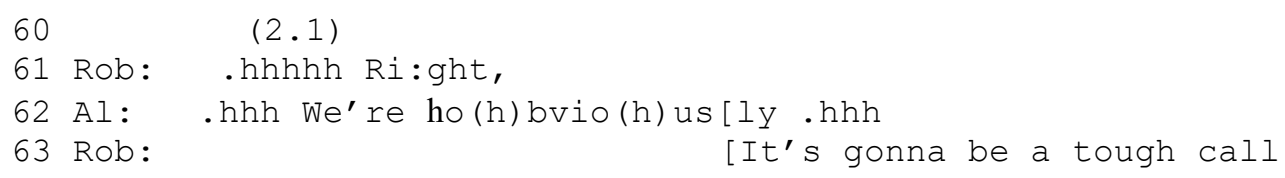

Robert eventually uses the information given, but here he begins to deliberate publicly about what to do. In making his indecision public, Robert embodies the sporting player by showing he is aware of the unfairness of his advantage.

Across the argument in the extracts above, we see players negotiating acceptable actions in the game. The central means of accounting that organizes the argument is whether the action was self-serving or altruistic, unfair competition or an attempt to helpfully share information. These are instantiations of the sporting device. Across the data corpus, players orient to the fairness of their strategies and the sportingness of their play. Players are ascribed to employ manipulation in multiple ways, which is vulnerable to moral sanction. The attribution of manipulation is also, itself, morally fraught, and players must avoid being seen as a complainer (Edwards 2005) even while putting an ascription on record.

\section{DISCUSSION}

This paper has analyzed how players negotiate the acceptability of employing and attributing deceit and manipulation during game play — a new investigation, as past analysis of game play has focused on the maintenance of roles (Linderoth 2012) and the negotiation of rules (Liberman 2013). In this paper, we have shown how a manipulation is attributed to a board game player, and described different ways of negotiating the acceptability of that action. In particular, players show orientations to managing whether they are being "sporting" in their behavior, such as showing ironic appreciation when suffering loss (Ext. 1), claiming awareness of manipulation (Ext. 1, 2), and using (un)fairness of competition and altruism as bases for complaint (Ext. 3). In doing so, we have expanded the literature in studies of interaction that concern the social 
organization of intention and action attribution (e.g., Edwards 2008; Jayyusi 1993; Reynolds and Rendle-Short 2010; Sidnell 2017).

We have shown that the manipulator is not the only party that can be made accountable during an attribution of a manipulation. The manipulated person, or player who was duped, can also end up accounting for not having seen through the performance of the manipulator (they have been "played," as in Ext. 2). All players must demonstrate some willingness to suffer loss, as well as win, even by the hand of manipulation or by the hand of revealing a strategy. Likewise, attributing manipulations can raise issues of fairness — whether a player has the opportunity for rebuttal or prevention, whether the player's strategy hinges more monumentally on that one manipulation succeeding, whether there are reasonable accounts for doing the attribution (such as explicit rules or targeting), and so on. Accepting accountability for a manipulation can act to progress the game forward and support the collaborative competition. On the other hand, there are instances where accepting the manipulation would strain the collaborative and contrived nature of the game too much (for a given player's perspective). The sporting resource helps both these scenarios, in providing a warrant for accepting accountability, but also a warrant for requiring a more sporting move. The management of being a sporting player, then, comes down to how and when one negotiates the acceptability of the action. This supports prior work that has found that players rely on the institutional context, or overarching activity, to negotiate the acceptability of game actions (Evans and Fitzgerald 2016).

There is a tension between the variety of roles a player may be said to have, such as being a strong (enough) competitor vs. an altruistic advisor. The players in our data are not strategic robots. It matters to them how the manipulation is framed and treated, and for a greater purpose than merely delegitimizing or preventing a move. In examining the interaction itself in detail, we 
have shown that players have to manage their stake and actions in attributing the manipulation (i.e., that the attribution is itself a concern for doing sporting play), and that discussion of the sportingness of the move finds meaning in the interactional accountability of the attribution. At the moment of attributing manipulation, who does the attributing, to whom, and how it is done all have their own interactional fallout; these actions all do something in interaction, and are not purely responsive to behavior that may be taken to be unsporting. To attribute is also to complain or potentially spark argument. This examination shows a different side to gaming interaction than strategic interaction and face management (Puddephatt 2003).

We question whether the magic circle (Stenros 2014) is an adequate explanation for the above data and analysis. The means by which players attributed and negotiated the impact of manipulations was via fairness, rather than validity. The negotiations did not display a concern that the manipulation was outside of the game (e.g., "metagaming," Bergström 2010), but instead were organized as though already part of the game. This is in part because all the manipulations were accomplished by interaction that accompanies the game, rather than through literal game moves (i.e., not a forced play like a check in chess, but non-move efforts such as smiling in a bluff, as in Ext. 2). The concern here is not validity (is it in the game?), but the degree to which a move furthers a good game. Furthermore, our analysis shows the difficulty in pinpointing which person, or which moment, "breaks" the magic circle and is then not acceptably part of the game.

Finally, the moral difficulties seen in the game were not special or distinct from everyday interaction. Concerns about avoiding being a complainer (Edwards 2005), giving altruistic and appropriately timed advice (Shaw and Hepburn 2013), and dealing with antagonism (Dersley and Wootton 2000) are phenomena that are documented outside the game context and work in the same way seen above. As Drew (1998) notes, morality is pervasively relevant in ordinary 
conversations, and as we have shown, there appears to be no magic circle so strong that it protects gameplayers from the accountability of moral concerns. Rather, participants negotiate, locally and for particular interactional purposes, how morality is relevant as their activities unfold.

We are limited to investigating attributions of manipulation, rather than including those moments where players might notice, but not publicly attribute, the same. However, we can still observe how players orient to upholding moral behavior, specifically sporting behavior, when the deceit is made public. This may be one of the only studies that analyzes attributed deception while still holding to the discursive principles of participant orientation. In doing so, we have learned how players are concerned with the reasonable continuation of the current activity, and how that impacts their moral reasoning. It is particularly interesting that attributed manipulations - in other words, manipulations that become part of intersubjective awarenesshave an accepted place in social organization, where sincerity and truthfulness are otherwise assumed to be present. While the contingencies noted here are likely limited to the context of play, it is a starting point for future work into the nature of deception and intention attribution (see also Edwards 2008; Reynolds and Rendle-Short 2010; Sidnell 2017).

\section{ACKNOWLEDGMENTS}

We thank the reviewers and panel audiences of the Language and Social Interaction Divisions at the National Communication Association and the International Communication Association for their helpful comments on earlier versions of this manuscript. Thank you to the members of the Discourse and Rhetoric Group for their contributions in early analyses. Thank you to the two anonymous reviewers of this paper, and the editor. Thank you to all the participants in our data.

\section{REFERENCES}


Bateman, Amanda, and Carly W. Butler. 2014. "The Lore and Law of the Playground." International Journal of Play 3(3):235-50.

Bateson, Gregory. [1972] 2006. “A Theory of Play and Fantasy.” Pp. 314-328 in The Game Design Reader: A Rules of Play Anthology, edited by Katie Salen and Eric Zimmerman. Cambridge: MIT Press.

Bergström, Karl. 2010. “The Implicit Rules of Board Games - on the Particulars of the Lusory Agreement." Presented at MindTrek, October 6-8, Tampere, Finland.

Davidson, Christina. 2012. 'When 'Yes' Turns to 'No': Young Children's Disputes During Computer Game Playing in the Home." Sociological Studies of Children and Youth 15:35576.

Dersley, Ian and Anthony Wootton. 2000. “Complaint Sequences within Antagonistic Argument." Research on Language and Social Interaction 33(4):375-406.

DiCicco-Bloom, Benjamin, and David R. Gibson. 2010. "More than a Game: Sociological Theory from the Theories of Games." Sociological Theory 28(3):247-71.

Edwards, Derek. 2005. “Moaning, Whinging, and Laughing: The Subjective Side of Complaints." Discourse Studies 7(1):5-29.

Edwards, Derek. 2008. "Intentionality and Mens Rea in Police Interrogations: The Production of Actions as Crimes." Intercultural Pragmatics 5(2):177-99.

Evaldsson, Ann-Carita. 2004. "Shifting Moral Stances: Morality and Gender in Same-Sex and Cross-Sex Game Interaction.” Research on Language \& Social Interaction 37(3):331-63.

Evans, Bryn, and Richard Fitzgerald. 2016. “'It’s Training Man’! Membership Categorization and the Institutional Moral Order of Basketball Training." Australian Journal of Linguistics $36(2): 205-23$. 
Fox, Barbara A., and Sandra A. Thompson. 2010. "Responses to Wh-Questions in English Conversation.” Research on Language \& Social Interaction 43(2):133-56.

Goffman, Erving. 1971. Strategic Interaction. Philadelphia: University of Philadelphia Press.

Goffman, Erving. 1974. Frame Analysis: An Essay on the Organization of Experience. Boston: Northeastern University Press.

Goodwin, Marjorie Harness. 1985. "The Serious Side of Jump Rope: Conversational Practices and Social Organization in the Frame of Play." The Journal of American Folklore 98(389):315-30.

Grice, Paul. 1975. "Logic and Conversation.” Pp. 41-58 in Syntax and Semantics (Vol. 3): Speech Acts, edited by P. Cole and J. L. Morgan. New York: Academic Press.

Heritage, John. 1990. “Intention, Meaning and Strategy: Observations on Constraints on Interaction Analysis.” Research on Language \& Social Interaction 24:311-22.

Hoey, Elliott. 2014. "Sighing in interaction: Somatic, Semiotic, and Social." Research on Language \& Social Interaction 47(2):175-200.

Holt, Elizabeth. 2012. "Using Laugh Responses to Defuse Complaints.” Research on Language \& Social Interaction 45(4):430-48.

Holt, Elizabeth. 2013. “"There's Many a True Word Said in Jest': Seriousness and Nonseriousness in Interaction.” Pp. 69-89 in Studies of Laughter in Interaction, edited by Phillip Glenn and Elizabeth Holt. London: Bloomsbury.

Huizinga, Johan. 1949. Homo Ludens: A Study of the Play-Element in Culture. Abingdon: Routledge \& Kegan Paul.

Jayyusi, Lena. 1993. "Premeditation and happenstance: The Social Construction of Intention, Action and Knowledge.” Human Studies 16:435-454. 
Jefferson, Gail. 1984a. "Transcript Notation.” Pp. x-xvi in Structures of Social Action: Studies in Conversation Analysis, edited by J. Maxwell Atkinson and John Heritage. Cambridge: Cambridge University Press.

Jefferson, Gail. 1984b. “On the Organization of Laughter in Talk about Troubles.” Pp. 346-369 in Structures of Social Action: Studies in Conversation Analysis, edited by J. Maxwell Atkinson and John Heritage. Cambridge: Cambridge University Press.

Kew, Francis. 1986. "Playing the Game: An Ethnomethodological Perspective.” International Review for Sociology of Sport 21(4):305-22.

Liberman, Kenneth. 2013. More Studies in Ethnomethodology. Albany, NY: SUNY Press. Linderoth, Jonas. 2012. "The Effort of Being in a Fictional World: Upkeyings and Laminated Frames in MMORPGs.” Symbolic Interaction 35(4):474-492.

Livingston, Eric. 2008. "Context and Detail in Studies of Witnessable Social Order: Puzzles, Maps, Checkers and Geometry.” Journal of Pragmatics 40:840-862.

Melia, Claire. 2015. "Laughter as a Mediator for Amicably Terminating Disagreements within Romantic Relationships." Undergraduate thesis, Department of Psychology, Keele University.

Mikesell, Lisa, Galina B. Bolden, Jenny Mandelbaum, Jeffrey D. Robinson, Tanya Romaniuk, Alexa Bolaños-Carpio, Darcey Searles, Wan Wei, Stephen M. DiDomenico, and Beth Angell. 2017. "At the Intersection of Epistemics and Action: Responding with I Know." Research on Language and Social Interaction 50(3):268-285.

Piirainen-Marsh, Arja, and Liisa Tainio. 2014. "Asymmetries of Knowledge and Epistemic Change in Social Gaming Interaction.” The Modern Language Journal 98(4):1022-38. Pomerantz, Anita. 1984. “Agreeing and Disagreeing with Assessments: Some Features of 
Preferred/Dispreferred Turn Shapes.” Pp. 57-101 in Structures of Social Action: Studies in Conversation Analysis, edited by J. Maxwell Atkinson and John Heritage. Cambridge:

Cambridge University Press.

Potter, Jonathan, and Alexa Hepburn. 2010. 'Putting Aspiration into Words: 'Laugh Particles,' Managing Descriptive Trouble and Modulating Action.” Journal of Pragmatics 42(6):1543-55.

Puddephatt, Anthony J. 2003. “Chess Playing as Strategic Activity.” Symbolic Interaction 26(2):263-284.

Reeves, Stuart, Christian Greiffenhagen, and Eric Laurier. 2016. "Video Gaming as Practical Accomplishment: Ethnomethodology, Conversation Analysis, and Play.” Topics in Cognitive Science 9(2):1-35.

Reynolds, Edward, and Johanna Rendle-Short. 2010. "Cues to Deception in Context: Response Latency/Gaps in Denials and Blame Shifting.” British Journal of Social Psychology 50:431-449.

Salen, Katie, and Eric Zimmerman. 2005. “Game Design and Meaningful Play.” Pp. 59-79 in Handbook of Computer Game Studies, edited by Joost Raessens and Jeffrey Goldstein. Cambridge: The MIT Press.

Sidnell, Jack. 2010. Conversation Analysis: An Introduction. Chichester: Wiley-Blackwell. Sidnell, Jack. 2011. “The Epistemics of Make-Believe.” Pp. 131-56 in The Morality of Knowledge in Conversation, edited by Phillip Glenn and Elizabeth Holt. Cambridge: Cambridge University Press.

Sidnell, Jack. 2017. “Action in Interaction Is Conduct under a Description.” Language in Society 46(3):313-337. 
Sidnell, Jack, and Nick J. Enfield. 2014. "The Ontology of Action, in Interaction.” Pp. 423-446 in The Cambridge Handbook of Linguistic Anthropology, edited by Nick Enfield, Paul Kockelman, and Jack Sidnell. Cambridge: Cambridge University Press.

Sierra, Sylvia. 2016. "Playing out Loud: Videogame References as Resources in Friend Interaction for Managing Frames, Epistemics, and Group Identity.” Language in Society 45:217-45.

Shaw, Chloe, and Alexa Hepburn. 2013. "Managing the Moral Implications of Advice in Informal Interaction.” Research on Language \& Social Interaction 46(4):344-362.

Stenros, Jaakko. 2014. “In Defence of a Magic Circle: The Social, Mental and Cultural Boundaries of Play." Transactions of the Digital Games Research Association 1(2):147185.

Stivers, Tanya, Lorenza Mondada, and Jakob Steensig, eds. 2011. The Morality of Knowledge in Conversation. Cambridge: Cambridge University Press.

Theobald, Maryanne, and Susan Danby. 2019. “'Well, Now I'm Upset': Moral and Social Orders in the Playground." Pp. 1-21 in Morality in Practice: Exploring Childhood, Parenthood and Schooling in Everyday Life, edited by Jakob Cromdal and M. Tholander. London: Equinox.

Viney, Rowena. 2015. “Everyday Interaction in Lesbian Households: Identity Work, Body Behaviour, and Action.” PhD dissertation, Department of Social Sciences, Loughborough University.

Waskul, Dennis, and Matt Lust. 2004. "Role-Playing and Playing Roles: The Person, Player, and Persona in Fantasy Role-Playing." Symbolic Interaction 27(3):333-356.

\section{ABOUT THE CONTRIBUTOR(S)}


Emily Hofstetter (PhD, Loughborough University) is a researcher at Linköping University in Sweden, examining embodiment and vocalization. Her doctoral dissertation, which analyzed interactions between British Members of Parliament and their constituents, won a dissertation award at the International Communication Association. She has collaborated with Elizabeth Stokoe on the Conversation Analytic Role-Play Method (CARM). Other projects she is working on include analyses of university health and safety inspections, and neonatal decision-making in doctor-patient interactions.

Jessica S. Robles (PhD, University of Colorado at Boulder) is a lecturer in the School of Social Sciences at Loughborough University, UK. Her research uses discourse and conversation analysis to examine the social organization of difference and its relevance to how people interactionally manage ordinary moral troubles in their everyday lives. This work has covered, for example, political disagreements, gift-exchange dilemmas, responses to racist talk, and complaints about social media and technology use. 